\title{
Evaluation of a candidate breast cancer associated SNP in ERCC4 as a risk modifier in BRCA I and BRCA2 mutation carriers. Results from the Consortium of Investigators of Modifiers of BRCA I/BRCA2 (CIMBA)
}

A Osorio*,I, RL Milne ${ }^{2}$, G Pita $^{3}$, P Peterlongo ${ }^{4,5}$, T Heikkinen $^{6}$, J Simard ${ }^{7}$, G Chenevix-Trench $^{8}$, AB Spurdle $^{8}$, $\mathrm{J} \mathrm{Beesley}^{8}, \mathrm{X} \mathrm{Chen}^{8}$, S Healey ${ }^{8}$, KConFab', SL Neuhausen ${ }^{10}$, YC Ding ${ }^{10}$, FJ Couch ${ }^{11,12}$, X Wang ${ }^{11}$, N Lindor ${ }^{13}$, S Manoukian ${ }^{4}$, M Barile ${ }^{14}$, A Viel ${ }^{15}$, L Tizzoni ${ }^{5,16}$, Cl Szabo ${ }^{17}$, L Foretova ${ }^{18}$, M Zikan ${ }^{19}$, K Claes ${ }^{20}$, MH Greene ${ }^{21}$, P Mai $^{21}$, G Rennert ${ }^{22}$, F Lejbkowicz ${ }^{22}$, O Barnett-Griness ${ }^{22}$, IL Andrulis ${ }^{23,24}$, H Ozcelik ${ }^{24}$, N Weerasooriya ${ }^{23}$, OCGN $^{23}$ A-M Gerdes ${ }^{25}$, M Thomassen ${ }^{25}$, DG Cruger ${ }^{26}$, MA Caligo ${ }^{27}$, E Friedman ${ }^{28,29}$, B Kaufman ${ }^{28,29}$, Y Laitman ${ }^{28}$, S Cohen ${ }^{28}$, T Kontorovich ${ }^{28}$, R Gershoni-Baruch ${ }^{30}$, E Dagan ${ }^{31,32}$, H Jernström ${ }^{33}$, MS Askmalm $^{34}$, B Arver ${ }^{35}$, B Malmer ${ }^{36}$, SWE-BRCA ${ }^{37}$, SM Domchek ${ }^{38}$, KL Nathanson ${ }^{38}$, J Brunet ${ }^{39}$, T Ramón y Cajal ${ }^{40}$, D Yannoukakos ${ }^{41}$, U Hamann ${ }^{42}$, HEBON ${ }^{37}$, FBL Hogervorst ${ }^{43}$, S Verhoef ${ }^{43}$, EB Gómez García ${ }^{44,45}$, JT Wijnen ${ }^{46,47}$, A van den Ouweland ${ }^{48}$, EMBRACE ${ }^{37}$, DF Easton ${ }^{49}$, S Peock ${ }^{49}$, M Cook ${ }^{49}$, CT Oliver $^{49}$, D Frost ${ }^{49}$, C Luccarini $^{50}$, DG Evans ${ }^{51}$, F Lalloo ${ }^{51}$, R Eeles ${ }^{52}$, G Pichert ${ }^{53}$, J Cook ${ }^{54}$, S Hodgson ${ }^{55}$, PJ Morrison ${ }^{56}$, F Douglas ${ }^{57}$, AK Godwin ${ }^{58}$, GEMO $59,60,61$, OM Sinilnikova ${ }^{59,60}$, L Barjhoux ${ }^{59,60}$, D Stoppa-Lyonnet ${ }^{61}$, V Moncoutier ${ }^{61}$,

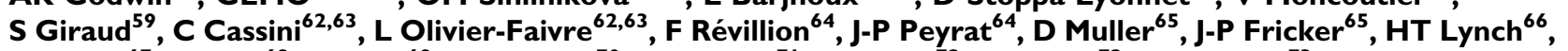
EM John ${ }^{67}$, S Buys ${ }^{68}$, M Daly ${ }^{69}$, JL Hopper ${ }^{70}$, MB Terry ${ }^{71}$, A Miron ${ }^{72}$, Y Yassin ${ }^{72}$, D Goldgar ${ }^{73}$, Breast Cancer Family Registry ${ }^{37}$, CF Singer ${ }^{74}$, D Gschwantler-Kaulich ${ }^{74}$, G Pfeiler $^{74}$, A-C Spiess ${ }^{74}$, Thomas v. O. Hansen ${ }^{75}$, OT Johannsson ${ }^{76}$, T Kirchhoff ${ }^{77}$, K Offit ${ }^{77}$, K Kosarin ${ }^{77}$, M Piedmonte ${ }^{78}$, GC Rodriguez ${ }^{79}$, K Wakeley ${ }^{80}$, JF Boggess ${ }^{81}$, J Basil ${ }^{82}$, PE Schwartz ${ }^{83}$, SV Blank ${ }^{84}$, AE Toland ${ }^{85}$, M Montagna ${ }^{86}$, C Casella ${ }^{87}$, EN Imyanitov ${ }^{88}$, A Allavena ${ }^{89}$, RK Schmutzler ${ }^{90}$, B Versmold ${ }^{90}$, C Engel ${ }^{91}$, A Meindl ${ }^{92}$, N Ditsch ${ }^{93}$, N Arnold ${ }^{94}$, D Niederacher ${ }^{95}$, H Deißler $^{96}$, B Fiebig ${ }^{97}$, R Varon-Mateeva ${ }^{98}$, D Schaefer ${ }^{99}$, UG Froster ${ }^{100}$, T Caldes ${ }^{101}$, M de la Hoya ${ }^{101}$, L McGuffog $^{49}$, AC Antoniou ${ }^{49}$, H Nevanlinna ${ }^{6}$, P Radice $^{4,5}$ and J Benítez ${ }^{1,3}$ on behalf of CIMBA

\begin{abstract}
'Human Genetics Group, Spanish National Cancer Research Centre, Madrid, Spain; ${ }^{2}$ Genetic and Molecular Epidemiology Group, Spanish National Cancer Research Centre, Madrid, Spain; ${ }^{3}$ Genotyping Unit, Human Cancer Genetics Programme, Spanish National Cancer Research Centre, Madrid, Spain; ${ }^{4}$ Fondazione IRCCS Istituto Nazionale Tumori, Milan, Italy; ${ }^{5}$ Fondazione Istituto FIRC di Oncologia Molecolare, Milan, Italy; ${ }^{6}$ Department of Obstetrics and Gynaecology, Helsinki University Central Hospital (HUCH), HelsVinki, Finland; ${ }^{7}$ Canada Research Chair in Oncogenetics, Cancer Genomics Laboratory, Centre Hospitalier Universitaire de Québec and Laval University, Québec, Canada; ${ }^{8}$ Division of Genetics and Population Health, Queensland Institute of Medical Research, Brisbane, Australia; ${ }^{9}$ Research Division, Peter MacCallum Cancer Center, Melbourne, Australia; ${ }^{10}$ Department of Epidemiology, School of Medicine, University of California Irvine, Irvine, CA, USA; "'Department of Laboratory Medicine and Pathology, Mayo Clinic, Rochester, MN, USA; ${ }^{12}$ Department of Health Sciences Research, Mayo Clinic, Rochester, MN, USA; ${ }^{13}$ Department of Medical Genetics, Mayo Clinic, Rochester, MN, USA; ${ }^{14}$ Istituto Europeo di Oncologia, Milan, Italy; ${ }^{15}$ Centro di Riferimento Oncologico, IRCCS, Aviano, PN, Italy; ${ }^{16} \mathrm{Cogentech,} \mathrm{Consortium}$ for Genomic Technologies, Milan, Italy; ${ }^{17}$ Department of Laboratory Medicine and Pathology, Mayo Clinic College of Medicine, Rochester, MN, USA; ${ }^{18}$ Department of Cancer Epidemiology and Genetics, Masaryk Memorial Cancer Institute, Brno, Czech Republic; ${ }^{19}$ Department of Biochemistry and Experimental Oncology, First Faculty of Medicine, Charles University, Prague, Czech Republic; ${ }^{20}$ Center for Medical Genetics, Ghent University Hospital, Ghent, Belgium; ${ }^{21}$ Clinical Genetics Branch, National Cancer Institute, Rockville, MD, USA; ${ }^{22}$ CHS National Cancer Control Center at Carmel Medical Center and Technion Faculty of Medicine, Haifa, Israel; ${ }^{23}$ Ontario Cancer Genetics Network (OCGN), Cancer Care Ontario, Toronto, ON, Canada; ${ }^{24}$ Fred A. Litwin Center for Cancer Genetics, Samuel Lunenfeld Research Institute, Mount Sinai, Toronto, ON, Canada; ${ }^{25}$ Clinical Genetics BFG, Odense University Hospital, Odense, Denmark; ${ }^{26}$ Department of Clinical Genetics, Vejle Hospital, Vijle, Denmark; ${ }^{27}$ Division of Pathology, Department of Oncology, University and University Hospital of Pisa, Pisa, Italy; ${ }^{28}$ Sheba Medical Centre (SMC), Tel Hashomer, Israel; ${ }^{29}$ The Sackler School of Medicine, Tel-Aviv University, Tel-Aviv, Israel; ${ }^{30}$ Rambam Medical Centre, Haifa, Israel; ${ }^{31}$ Department of Nursing, Faculty of Social Welfare and Health Sciences, University of Haifa, Haifa, Israel; ${ }^{32}$ Rambam Health Care Campus, Institute of Human Genetics, Haifa, Israel; ${ }^{33}$ Department of Oncology, Clinical Sciences, Lund University, Lund, Sweden; ${ }^{34}$ Department of Oncology, University Hospital, Linköping, Sweden; ${ }^{35}$ Department of Oncology, Karolinska University Hospital, Stockholm, Sweden; ${ }^{36}$ Department of Radiation Sciences, Oncology, Umeå University, Umeå, Sweden; ${ }^{37}$ See acknowledgements; ${ }^{38}$ Abramson Cancer Center, University of Pennsylvania, Philadelphia, PA, USA; ${ }^{39}$ Programa de Consejo Genético en Cáncer, Instituto Catalán de Oncología, Hospital Dr Josep Trueta-ldiBGi, Gerona, Spain; ${ }^{40}$ Servicio de Oncología Médica del Hospital de la Santa Creu i Sant Pau, Barcelona, España; ${ }^{41}$ IRRP, National Centre for
\end{abstract}

* Correspondence: Dr A Osorio, Human Genetics Group, Spanish National Cancer Centre (CNIO), C/Melchor Fernández Almagro 3, 28029 Madrid, Spain; E-mail: aosorio@cnio.es

Received 5 August 2009; accepted 12 October 2009; published online

17 November 2009 
Scientific Research 'Demokritos', Molecular Diagnostics Laboratory, Athens, Greece; ${ }^{42}$ Molecular Genetics of Breast Cancer, Deutsches

Krebsforschungszentrum (DKFZ), Heidelberg, Germany; ${ }^{43}$ Department of Clinical Molecular Genetics, Family Cancer Clinic, Netherlands Cancer Institute, Amsterdam, NL, USA; ${ }^{44}$ Department of Genetics and Cell Biology, University Medical Centre, Maastricht, NL; ${ }^{45}$ Research Institute Growth and Development (GROW), Maastricht, NL, USA; ${ }^{46}$ Department Clinical Molecular Genetics, Leiden University Medical Center, Leiden, NL, USA;

${ }^{47}$ Department of Human Genetic, Leiden University Medical Center, Leiden, NL, USA; ${ }^{48}$ Department of Molecular Genetics, Erasmus University Medical Center, Rotterdam, NL, USA; ${ }^{49}$ Department of Public Health and Primary Care, Cancer Research UK Genetic Epidemiology Unit, University of Cambridge, Cambridge, UK; ${ }^{50}$ Department of Oncology, University of Cambridge, Cambridge, UK; ${ }^{51}$ Academic Unit of Medical Genetics and Regional Genetics Service, St Mary's Hospital, Manchester, UK; ${ }^{52}$ Translational Cancer Genetics Team, The Institute of Cancer Research and Royal Marsden NHS Foundation Trust, London, UK; ${ }^{53}$ Clinical Genetics, Guy's Hospital, London, UK; ${ }^{54}$ Sheffield Clinical Genetics Service, Sheffield Children's Hospital, Sheffield, UK; ${ }^{55}$ Department of Cancer Genetics, St Georges Hospital, University of London, London, UK; ${ }^{56}$ Northern Ireland Regional Genetics Centre, Belfast City Hospital, Belfast, UK; ${ }^{57}$ Institute of Human Genetics, Centre for Life, Newcastle Upon Tyne Hospitals NHS Trust, Newcastle upon Tyne, UK; ${ }^{58}$ Fox Chase Cancer Center, Philadelphia, PA, USA; ${ }^{59}$ Unité Mixte de Génétique Constitutionnelle des Cancers Fréquents, Hospices Civils de Lyon/Centre Léon Bérard, Lyon, France; ${ }^{60}$ Laboratoire de Génétique Moléculaire, Signalisation et Cancer, UMR520I CNRS, Université de Lyon, Lyon, France; ${ }^{61}$ INSERM U509, Service de Génétique Oncologique, Institut Curie, Université Paris-Descartes, Paris, France; ${ }^{62}$ Centre de Génétique, Dijon, France; ${ }^{63} \mathrm{CLCC}$ Georges François Leclerc, Dijon, France; ${ }^{64}$ Human Molecular Oncology Laboratory, Centre Oscar Lambret, Lille, France; ${ }^{65}$ Unité d'Oncogénétique, CLCC Paul Strauss, Strasbourg, France; ${ }^{66}$ Department of Preventive Medicine, Creighton University, Omaha, NE, USA; ${ }^{67}$ Northern California Cancer Center, Fremont, CA, USA; ${ }^{68}$ Huntsman Cancer Institute, Salt Lake City, UT, USA; ${ }^{69}$ Fox Chase Cancer Center, Philadelphia, PA, USA; ${ }^{70}$ University of Melbourne, Melbourne, Australia; ${ }^{71}$ Columbia University New York, NY, USA; ${ }^{72}$ Dana Farber Cancer Institute, Boston, MA, USA; ${ }^{73}$ Department of Dermatology, University of Utah, Salt Lake City, UT, USA; ${ }^{74}$ Division of Special Gynecology, Department of OB/GYN, Medical University of Vienna, Vienna, Austria; ${ }^{75}$ Department of Biochemistry, Pharmacology, and Genetics, Odense University Hospital, Odense, Denmark; ${ }^{76}$ Department of Oncology, Landspitali-University Hospital, Reykjavik, Iceland (OTh); ${ }^{77}$ Department of Medicine, Clinical Genetics Service, Memorial Sloan-Kettering Cancer Center, New York, NY, USA; ${ }^{78}$ GOG Statistical and Data Center, Roswell Park Cancer Institute, Buffalo, NY, USA; ${ }^{79}$ NorthShore University Health System, Evanston Northwestern Healthcare, Evanston, IL, USA; ${ }^{80}$ Tufts University, New England Medical Center, Boston, MA, USA; ${ }^{81}$ University of North Carolina, Chapel Hill, NC, USA; ${ }^{82}$ St Elizabeth Medical Center, Edgewood, KY, USA; ${ }^{33}$ Yale University School of Medicine, New Haven, CT, USA; ${ }^{44}$ New York University School of Medicine, New York, NY, USA; ${ }^{85}$ Division of Human Cancer Genetics, Departments of Internal Medicine and Molecular Virology, Immunology and Medical Genetics, Comprehensive Cancer Center, The Ohio State University, Columbus, OHIO, USA; ${ }^{86}$ Instituto Oncologico Veneto - IRCCS, Padua, Italy; ${ }^{87}$ Department of Oncology and Surgical Sciences, Padua, Italy; ${ }^{8}$ N.N. Petrov Institute of Oncology, St-Petersburg, Russia; ${ }^{89}$ Department of Genetics, Biology and Biochemistry, University of Turin, Turin, Italy; ${ }^{90}$ Division of Molecular Gynaeco-Oncology, Department of Obstetrics and Gynaecology, University of Cologne, Cologne, Germany; ${ }^{91}$ Institute for Medical Informatics, Statistics and Epidemiology, University of Leipzig, Germany; ${ }^{92}$ Department of Obstetrics and Gynaecology, Technical University Munich, Munich, Germany; ${ }^{93}$ Department of Obstetrics and Gynaecology, Ludwig-Maximilian University Munich, Munich, Germany; ${ }^{94}$ Department of Obstetrics and Gynaecology, University of Schleswig-Holstein, Campus Kiel, Germany; ${ }^{95}$ Department of Obstetrics and Gynaecology, Molecular Genetics Laboratory, University of Duesseldorf, Dusseldorf, Germany; ${ }^{96}$ Department of Obstetrics and Gynaecology, University of Ulm, Ulm, Germany; ${ }^{97}$ University of Regensburg, Institute of Human Genetics, Regensburg, Germany; ${ }^{98}$ Institute of Human Genetics, Charité, Humboldt University, Berlin, Germany; ${ }^{99}$ Institute of Human Genetics, University of Frankfurt, Frankfurt, Germany; ${ }^{100}$ Institute of Human Genetics, University of Leipzig, Leipzig, Germany; ${ }^{101}$ Hospital Clínico San Carlos, Madrid, Spain.

BACKGROUND: In this study we aimed to evaluate the role of a SNP in intron I of the ERCC4 gene (rs744I 54), previously reported to be associated with a reduced risk of breast cancer in the general population, as a breast cancer risk modifier in BRCA I and BRCA2 mutation carriers.

METHODS: We have genotyped rs744I54 in 9408 BRCA / and 5632 BRCA2 mutation carriers from the Consortium of Investigators of Modifiers of BRCA //2 (CIMBA) and assessed its association with breast cancer risk using a retrospective weighted cohort approach. RESULTS: We found no evidence of association with breast cancer risk for BRCA I (per-allele HR: 0.98, 95\% Cl: 0.93- I.04, $P=0.5$ ) or BRCA2 (per-allele HR: 0.97, 95\% Cl: 0.89-1.06, $P=0.5$ ) mutation carriers.

CONCLUSION: This SNP is not a significant modifier of breast cancer risk for mutation carriers, though weak associations cannot be ruled out. British Journal of Cancer (2009) I 0 I, 2048-2054. doi: I0.1038/sj.bjc.66054I6 www.bjcancer.com

Published online 17 November 2009

(c) 2009 Cancer Research UK

Keywords: BRCA I; BRCA2; ERCC4; breast cancer

Germ-line mutations in the BRCA1 and BRCA2 genes confer a high lifetime risk of developing breast and other cancers. Estimates of the cumulative risk of breast cancer to age 70 years vary from $40 \%$ to $85 \%$ (Easton et al, 1995; Ford et al, 1998; Antoniou et al, 2003; Chen et al, 2006; Milne et al, 2008). Other genetic and/or environmental factors (modifiers) are likely to explain these differences, at least in part. Because of the large sample size required to identify such effects, few reliable associations have been reported to date, all coming from the Consortium of Investigators of Modifiers of BRCA1/2 (CIMBA) initiative, which was set up to provide large samples of BRCA1 and BRCA2 mutation carriers to reliably assess even modest associations with single nucleotide polymorphisms (SNPs) (Chenevix-Trench et al, 2007). Recently, CIMBA assessed three SNPs in the FGFR2, TNRC9 and MAP3K1 genes that had been previously found by a genome- wide association study to be associated with increased breast cancer risk for women in the general population (Easton et al, 2007). Consistent associations were found for $B R C A 1$ and/or BRCA2 mutation carriers (Antoniou et al, 2008), indicating that SNPs involved in the susceptibility to develop breast cancer in the general population are good candidates to be tested as potential modifiers in BRCA1 and BRCA2 mutation carriers.

The ERCC4 gene is involved in the nucleotide excision repair (NER) pathway, which has led to the investigation of its role in the susceptibility to develop different types of cancer including breast cancer (Garcia-Closas et al, 2006; Mechanic et al, 2006; Moreno et al, 2006; Kiyohara and Yoshimasu, 2007; Hooker et al, 2008; Smith et al, 2008). We previously reported that the minor $\mathrm{G}$ allele in a SNP on intron 1 of ERCC4 (rs744154) was associated with protection from breast cancer in the general population (OR under 
a recessive model $0.61 ; P=0.0002$ ) (Milne et al, 2006). On the basis of this finding, we aimed to assess ERCC4-rs744154 as a breast cancer risk modifier in $B R C A 1$ and $B R C A 2$ mutation carriers. The study was performed in two stages, the first comprising 837 mutation carriers from three CIMBA centres, and the second comprising 15040 mutation carriers from all the CIMBA studies, including those used in stage I.

\section{MATERIALS AND METHODS}

\section{Subjects}

Eligible subjects were female carriers of deleterious mutations in $B R C A 1$ and BRCA2 aged 18 years or older. Further details regarding eligibility and the information collected from subjects are described elsewhere (Antoniou et al, 2008). Subjects who reported having ethnicity other than White European were excluded. This gave a total of 15040 female mutation carriers (9408 with mutations in BRCA1 and 5632 with mutations in $B R C A 2), 8088$ of whom had been diagnosed with breast cancer (4956 and 3132 with mutations in BRCA1 and BRCA2, respectively). All carriers participated in clinical or research studies at the host institution under ethically approved protocols.

A total of 34 collaborating CIMBA studies, carried out in 18 countries, contributed genotype data for ERCC4-rs744154 to this study. Details of each study along with the number of samples included from each are provided in Table 1. Seven studies (CBCS,
GOG, ILUH, MSKCC, NNPIO, OSUCCG and IOVHBOCS) had not participated in previous CIMBA collaborations (Antoniou et al, 2008). Subjects from the CNIO, HEBCS and MBCSG studies were used in the first stage and comprised 837 mutation carriers (469 in $B R C A 1$ and 368 in BRCA2). All 9408 BRCA1 and 5632 BRCA2 mutation carriers CIMBA subjects were included in the second stage.

\section{Genotyping}

The genotyping platform used by each study is detailed in Table 1. For 11 studies, matrix-assisted laser desorption/ionization time of flight mass spectrometry (MALDI-TOF MS) was applied to determine allele-specific primer extension products using Sequenom's MassARRAY system and iPLEX technology (Sequenom, San Diego, CA, USA). The design of oligonucleotides was carried out according to the guidelines of Sequenom and performed using MassARRAY Assay Design software (version 3.1). One study determined genotypes by direct sequencing. Genotyping was carried out for the remaining studies by nuclease assay (Taqman). Taqman genotyping reagents were designed by Applied Biosystems (Foster City, CA, USA) (http://www.appliedbiosystems.com/) as Assays-by-Design. Genotyping was performed using the ABI PRISM 7900HT, 7700 or 7500 Sequence Detection Systems according to the manufacturer's instructions. All studies complied with CIMBA genotyping quality control (QC) standards (Antoniou et al, 2008).

Table I Number of BRCAI and BRCA2 mutation carriers by study

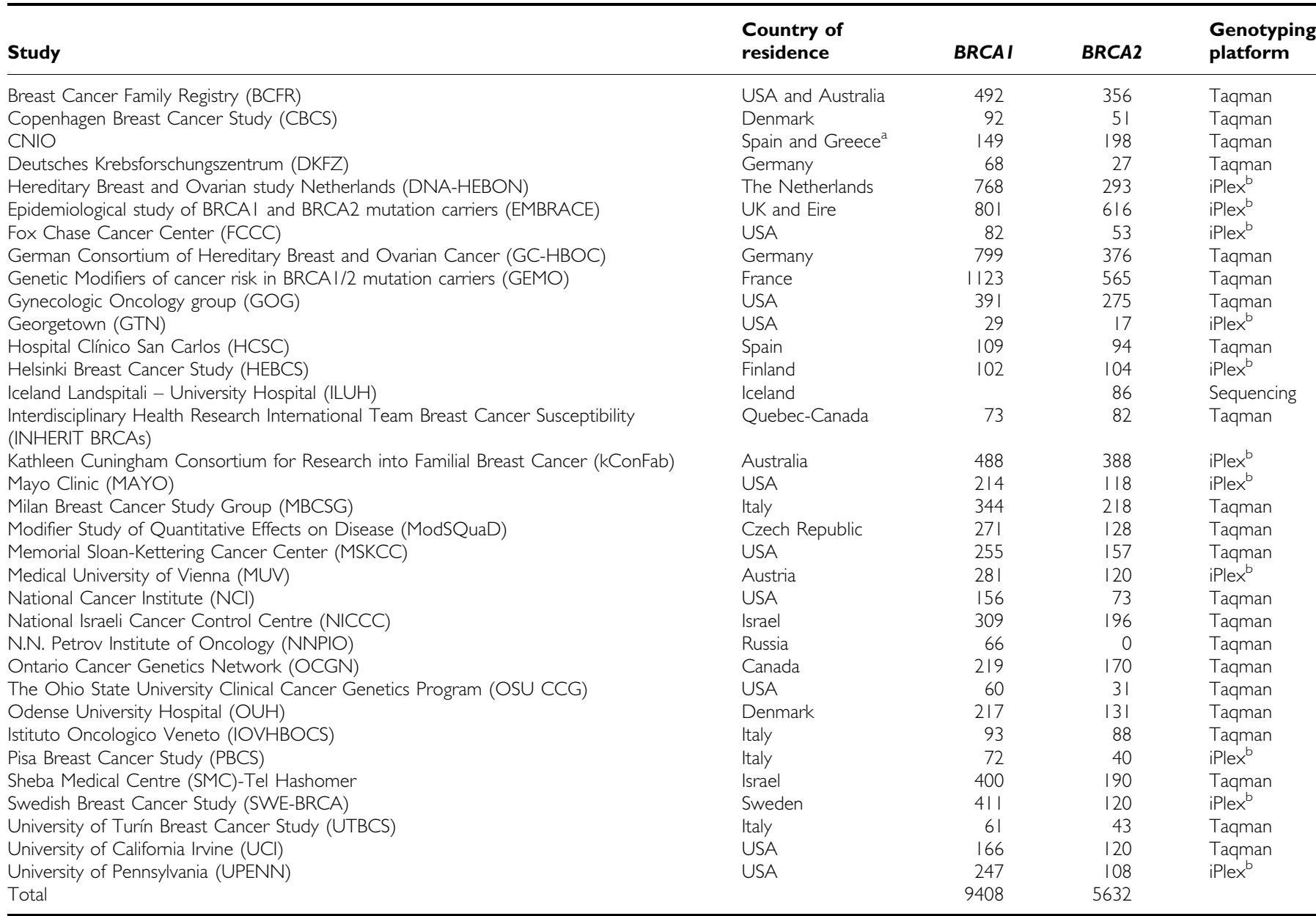

aThe CNIO series consisted of mutation carriers from the Spanish Consortium for the Study of Genetic Modifiers of BRCA I and BRCA2 and the NCSR Demokritos, Athens, Greece. bMutation carriers that failed genotyping are not included in the totals. 


\section{Statistical analysis}

To test for departure from Hardy - Weinberg equilibrium, a single subject was randomly selected from each family and Pearson's $\chi^{2}$ Test (1 d.f.) was applied to genotypes from this sample set. The association of ERCC4-rs744154 with breast cancer risk was assessed by estimating hazard ratios (HR) and their corresponding 95\% confidence intervals (CI) using weighted multivariable Cox proportional hazards regression with robust estimates of variance (Antoniou et al, 2005). For each mutation carrier, we modelled the time to diagnosis of breast cancer from birth, censoring at the first of the following events: bilateral prophylactic mastectomy, breast cancer diagnosis, ovarian cancer diagnosis, death and last date known to be alive. Subjects were considered affected if they were censored at breast cancer diagnosis and unaffected otherwise. The weighted cohort approach involves assigning weights separately to affected and unaffected individuals such that the weighted observed incidences in the sample agree with established estimates for mutation carriers (Antoniou et al, 2003). This approach has been shown to adjust for the bias in the HR estimates that is a consequence of the ascertainment criteria used (Antoniou et al, 2005), which leads to an over-sampling of affected women. Weights were assigned separately for carriers of mutations in $B R C A 1$ and BRCA2 and by age interval $(<25,25-29,30-34,35-$ $39,40-44,45-49,50-54,55-59,60-64,65-69, \geqslant 70)$.

We considered log-additive and codominant genetic models and tested these by applying in the first case a Wald test based on the log-HR estimate per allele and its standard error, and in the second the $\chi^{2}$ equivalent of a Wald test (on 2 degrees of freedom [d.f.]) based on the log-HR estimates for heterozygotes (CG) and minorallele-homozygotes (GG) vs common homozygotes (CC) and the corresponding variance-covariance matrix. Additional independent variables included in all analyses were year of birth $(<1930$, $1930-1939,1940-1949,1950-1959,1960-1969, \geqslant 1970)$, study centre and country. Heterogeneity in HRs by study centre was assessed by the $\chi^{2}$ test described above, but applied to interaction terms for the per-allele effect by centre (on 33 d.f.). A number of sensitivity analyses were applied, including censoring at bilateral prophylactic oophorectomy (BPO), adjusting for BPO (as a timevarying covariate), excluding data used in the initial analysis (from CNIO, HEBCS and MBCSG) and excluding prevalent cases, defined as those diagnosed $>3$ years before interview or DNA extraction.
In addition, an alternative analysis based on a previously described retrospective likelihood approach (Chenevix-Trench et al, 2007) was also applied using the pedigree analysis software MENDEL (Lange et al, 1988).

All statistical analyses were carried out using Stata: Release 10 (StataCorp. 2007. Stata Statistical Software: Release 10.0. College Station, TX: Stata Corporation LP) unless otherwise stated. Robust estimates of variance were calculated using the cluster subcommand, applied to an identifier variable unique to each family.

\section{RESULTS AND DISCUSSION}

It is thought that any SNP involved in the susceptibility to develop breast cancer in the general population could also be a phenotypic modifier in carriers of mutations in the high-risk susceptibility genes BRCA1 and BRCA2. This has been confirmed in a recent report from CIMBA in which minor alleles in three SNPs in the FGFR2, TNRC9 and MAP3K1 genes, previously found to be associated with increased breast cancer risk in the general population (Easton et al, 2007), were found to increase breast cancer risk in BRCA1 and/or BRCA2 mutation carriers as well (Antoniou et al, 2008). We therefore aimed to investigate the role of the rs744154 SNP in ERCC4 as a potential BRCA1/BRCA2 risk modifier, based on our earlier finding that the minor $G$ allele was associated with breast cancer protection in the general population (OR under a recessive model $0.61 ; P=0.0002$ ) (Milne et al, 2006).

This study was performed in two stages, the first analysing the SNP in 837 carriers of mutations (469 in BRCA1 and 368 in BRCA2) from three CIMBA studies (CNIO, HEBCS and MBCSG). Results of the first stage are summarized in Table 2 . We observed a marginally significant association of the $\mathrm{G}$ allele in ERCC4rs744154 with breast cancer risk for both BRCA1 (HR: 0.78, 95\% CI: $0.60-1.00, P=0.05$ ) and BRCA2 (HR: $0.68,95 \%$ CI: $0.45-1.02$, $P=0.06)$ mutation carriers. As this result was consistent with our previously reported protective association in the general population (Milne et al, 2006), we genotyped this SNP in subjects from the remaining CIMBA studies and repeated the analysis in the combined series of $9408 B R C A 1$ and 5632 BRCA 2 mutation carriers (see Table 2). However, when the whole CIMBA series was analysed (stage II), there was no longer evidence of an association with breast cancer risk for either BRCA1 (HR: 0.98, 95\% CI: $0.93-$

Table 2 Genotype frequencies of ERCC4-rs744I54 by mutation and disease status and hazard ratio estimates from stages I and II

\begin{tabular}{|c|c|c|c|c|c|c|}
\hline & Genotype & Unaffected (\%) & Affected (\%) & $\mathbf{H R}^{\mathrm{a}}$ & $95 \% \mathrm{Cl}$ & $P$-value \\
\hline $\operatorname{BRCA2}(n=368)$ & $\begin{array}{l}\text { CC } \\
\text { CG } \\
\text { GG } \\
\text { Per allele }\end{array}$ & $\begin{array}{l}73(45) \\
81(49) \\
10(6)\end{array}$ & $\begin{array}{r}109(53) \\
82(40) \\
13(6)\end{array}$ & $\begin{array}{l}1.00 \\
0.66 \\
0.50 \\
0.68\end{array}$ & $\begin{array}{l}0.40-1.09 \\
0.17-1.47 \\
0.45-1.02\end{array}$ & $\begin{array}{l}0.2^{b} \\
0.06\end{array}$ \\
\hline $\begin{array}{l}\text { Stage } \| \\
\quad \text { BRCAI }(n=9408)\end{array}$ & $\begin{array}{l}\text { CC } \\
\text { CG } \\
\text { GG } \\
\text { Per allele }\end{array}$ & $\begin{array}{l}225 \mid(5 \mid) \\
1836(4 \mid) \\
365(8)\end{array}$ & $\begin{array}{c}2603(53) \\
1922(39) \\
431(9)\end{array}$ & $\begin{array}{l}1.00 \\
0.99 \\
0.96 \\
0.98\end{array}$ & $\begin{array}{l}0.92-1.07 \\
0.83-1.10 \\
0.93-1.04\end{array}$ & $\begin{array}{l}0.8^{\mathrm{b}} \\
0.5\end{array}$ \\
\hline
\end{tabular}

a 837 mutation carriers from CNIO, MBCSG and HBCS were included in stage I. Additional mutation carriers from these centres were later genotyped and included in stage II, with carriers from other CIMBA centres. Total number of mutation carriers from these three centres included in the study is provided in Table 1. ' 2 -d.f. test. 
1.04, $P=0.5$ ) or BRCA2 (HR: $0.97,95 \%$ CI: $0.89-1.06, P=0.5$ ) mutation carriers. Several sensitivity analyses were performed (see Materials and Methods) but results did not change substantially and so those from the main analysis are presented in this report.

Subsequent to the initiation of this study, a study from the Breast Cancer Association Consortium (BCAC), performed in $>30000$ breast cancer cases and 30000 controls has now found no evidence for an association of rs744154 with breast cancer risk in the general population (Gaudet et al, 2009). This is consistent with the lack of association found for BRCA1 and BRCA2 mutation carriers. These findings highlight the necessity of very large collaborative efforts to obtain reliable conclusions in genetic association studies. On the basis of the combined results obtained from the BCAC analysis of sporadic breast cancer and the CIMBA analysis of BRCA-related breast cancer - each the largest study of its kind - there no longer seems to be convincing evidence that ERCC4-rs744154 is associated with breast cancer risk.

\section{ACKNOWLEDGEMENTS}

Spanish National Cancer Centre (CNIO): We thank RM Alonso for her excellent technical assistance. The samples studied at CNIO were recruited by the Spanish Consortium for the Study of Genetic Modifiers of BRCA1 and BRCA2. This study was partially supported by Mutua Madrileña and Marató TV Foundations.

Milan Breast Cancer Study Group (MGCSG). MBCSG is supported by grants from Fondazione Italiana per la Ricerca sul Cancro (FIRC, Special Project 'Hereditary tumors'), Associazione Italiana per la Ricerca sul Cancro (AIRC) and the Italian Ministry of Health. MBCSG acknowledges Marco Pierotti, Bernard Peissel, Daniela Zaffaroni and Carla B Ripamonti of the Fondazione IRCCS Istituto Nazionale dei Tumori,Milan, Italy, Bernardo Bonanni of the Istituto Europeo di Oncologia, Milan, Italy and Loris Bernard of the Cogentech, Consortium for Genomic Technologies, Milan, Italy.

Interdisciplinary Health Research International Team Breast Cancer Susceptibility (INHERIT BRCAs): Jacques Simard, Francine Durocher, Rachel Laframboise, Marie Plante, Centre Hospitalier Universitaire de Quebec and Laval University, Quebec, Canada; Peter Bridge, Jilian Parboosingh, Molecular Diagnostic Laboratory, Alberta Children's Hospital, Calgary, Canada; Jocelyne Chiquette, Hôpital du Saint-Sacrement, Quebec, Canada; Bernard Lesperance, Hôpital du Sacré-Cœur de Montréal, Montréal, Canada. Jacques Simard-JS is Chairholder of the Canada Research Chair in Oncogenetics. This work was supported by the Canadian Institutes of Health Research for the 'CIHR Team in Familial Risks of Breast Cancer' program.

The Kathleen Cunningham Consortium for Research into Familial Breast Cancer (kConFab): We thank Heather Thorne, Eveline Niedermayr, all the kConFab research nurses and staff, the heads and staff of the Family Cancer Clinics, and the Clinical Follow-Up Study (funded by NHMRC grants 145684, 288704 and 454508) for their contributions to this resource, and the many families who contribute to kConFab. kConFab is supported by grants from the National Breast Cancer Foundation, the National Health and Medical Research Council (NHMRC) and by the Queensland Cancer Fund, the Cancer Councils of New South Wales, Victoria, Tasmania and South Australia, and the Cancer Foundation of Western Australia. ABS is an NHMRC Senior Research Fellow, and GCT is an NHMRC Senior Principal Research Fellow.

SL Neuhausen and YC Ding were supported by NIH CA74415.

MAYO study is supported in part by National Institute of Health Grants CA116167, CA122340, CA128978, a Sponsored Program of Research Excellence (SPORE) grant in Breast Cancer P50 CA116201, a grant from the Breast Cancer Research Foundation, and a grant from the Komen Foundation for the Cure.
Modifier Study of Quantitative Effects on Disease (ModSQuaD): CI Szabo is supported by the Mayo Rochester Early Career Development Award for Non-Clinician Scientists. We acknowledge the contributions of Petr Pohlreich and Zdenek Kleibl (Department of Biochemistry and Experimental Oncology, First Faculty of Medicine, Charles University, Prague, Czech Republic) and the support of the Research Project of the Ministry of Education, Youth, and Sports of the Czech Republic grant MSM0021620808 (to MZ, Zdenek Kleibl, and Petr Pohlreich). Lenka Foretova, Machackova Eva, and Lukesova Miroslava's are supported through the Ministry of Health grant CR-MZ0 MOU 2005. We acknowledge the contribution of Kim De Leeneer, Bruce Poppe and Anne De Paepe. This research was supported by grant 1.5.150.07 from the Fund for Scientific Research Flanders (FWO) to Kathleen Claes and by grant 12051203 from the Ghent University to Anne De Paepe. Bruce Poppe is Senior Clinical Investigator of the Fund for Scientific Research of Flanders (FWO - Vlaanderen).

National Cancer Institute (NCI): The research of Drs MH Greene and PL Mai is supported by the Intramural Research Program of the US National Cancer Institute, and by support services contracts NO2-CP-11019-50 and N02-CP-65504 with Westat, Inc, Rockville, MD. Genotyping of NCI DNA samples was performed by NCI's Core Genotyping Facility.

Ontario Cancer Genetics Network (OCGN): We thank Mona Gill, Teresa Selander, Gord Glendon, Elaine Maloney and members of the Ontario Cancer Genetics Network for their contributions to the study.

Odense University Hospital (OUH): Lone Sunde, Aarhus University Hospital, Denmark, is acknowledged for sending patient material to this study.

The Swedish BRCA1 and BRCA2 study collaborators (SWE$B R C A$ ): Per Karlsson, Margareta Nordling, Annika Bergman and Zakaria Einbeigi, Gothenburg, Sahlgrenska University Hospital; Marie Stenmark-Askmalm and Sigrun Liedgren, Linkoping University Hospital; Ake Borg, Niklas Loman, Hakan Olsson, Ulf Kristoffersson, Helena Jernstrom, Katja Harbst and Karin Henriksson, Lund University Hospital; Annika Lindblom, Brita Arver, Anna von Wachenfeldt, Annelie Liljegren, Gisela Barbany-Bustinza and Johanna Rantala, Stockholm, Karolinska University Hospital Beatrice Malmer, Eva-Lena Stattin and Monica Emanuelsson, Umea University Hospital; Hans Ehrencrona, Richard Rosenquist Brandell and Niklas Dahl, Uppsala University Hospital.

UPENN study is supported by the Breast Cancer Research Foundation.

The Hereditary Breast and Ovarian Cancer Research Group Netherlands (HEBON): HEBON collaborating centres: Coordinating centre: Netherlands Cancer Institute, Amsterdam: Frans Hogervorst, Senno Verhoef, Anouk Pijpe, Laura van 't Veer, Flora van Leeuwen, Matti Rookus; Erasmus Medical Center, Rotterdam: Margriet Collée, Ans van den Ouweland, Mieke Kriege, Mieke Schutte, Maartje Hooning, Caroline Seynaeve; Leiden University Medical Center, Leiden: Rob Tollenaar, Christi van Asperen, Juul Wijnen, Maaike Vreeswijk, Peter Devilee; Radboud University Nijmegen Medical Center, Nijmegen: Nicoline Hoogerbrugge, Marjolijn Ligtenberg; University Medical Center Utrecht, Utrecht: Margreet Ausems, Rob van der Luijt; Amsterdam Medical Center: Cora Aalfs, Theo van Os; VU University Medical Center, Amsterdam: Hanne Meijers-Heijboer, Hans Gille; University Hospital Maastricht, Maastricht: Encarna Gomez-Garcia, Rien Blok. The HEBON study is supported by the Dutch Cancer Society grants NKI1998-1854, NKI2004-3088, NKI 2007-3756.

Epidemiological study of BRCA1 and BRCA2 mutation carriers (EMBRACE): EMBRACE is supported by Cancer Research UK Grants C1287/A10118 and C1287/A8874. CL is supported by Cancer Research UK Grant C8197/A10123. The Investigators at The Institute of Cancer Research and The Royal Marsden NHS Foundation Trust are supported by an NIHR grant to the Biomedical Research Centre at The Institute of Cancer Research 
and The Royal Marsden NHS Foundation Trust. RE/EB/L D'M are also supported by Cancer Research UK Grant C5047/A8385. DGE and FL are supported by an NIHR grant to the Biomedical Research Centre, Manchester. DE is the PI of the study. EMBRACE collaborating centres are: Coordinating Centre, Cambridge: Susan Peock, Margaret Cook, Clare Oliver, Debra Frost. North of Scotland Regional Genetics Service, Aberdeen: Zosia Miedzybrodzka, Helen Gregory. Northern Ireland Regional Genetics Service, Belfast: Patrick Morrison. West Midlands Regional Clinical Genetics Service, Birmingham: Trevor Cole, Carole McKeown, Amy Taylor. South West Regional Genetics Service, Bristol: Alan Donaldson. East Anglian Regional Genetics Service, Cambridge: Joan Paterson. Medical Genetics Services for Wales, Cardiff: Alexandra Murray, Mark Rogers, Emma McCann. St James's Hospital, Dublin and National Centre for Medical Genetics, Dublin: John Kennedy, David Barton. South East of Scotland Regional Genetics Service, Edinburgh: Mary Porteous. Peninsula Clinical Genetics Service. Exeter: Carole Brewer, Emma Kivuva, Anne Searle, Selina Goodman. West of Scotland Regional Genetics Service, Glasgow: Rosemarie Davidson, Victoria Murday, Nicola Bradshaw, Lesley Snadden, Mark Longmuir, Catherine Watt. South East Thames Regional Genetics Service, Guys Hospital London: Louise Izatt, Gabriella Pichert, Caroline Langman. North West Thames Regional Genetics Service. Harrow: Huw Dorkins. Leicestershire Clinical Genetics Service, Leicester: Julian Barwell. Yorkshire Regional Genetics Service, Leeds: Carol Chu, Tim Bishop, Julie Miller. Merseyside and Cheshire Clinical Genetics Service. Liverpool: Ian Ellis. Manchester Regional Genetics Service, Manchester: D Gareth Evans, Fiona Lalloo, Felicity Holt. North East Thames Regional Genetics Service, NE Thames: Alison Male, Anne Robinson. Nottingham Centre for Medical Genetics, Nottingham: Carol Gardiner. Northern Clinical Genetics Service, Newcastle: Fiona Douglas, Oonagh Claber. Oxford Regional Genetics Service, Oxford: Lisa Walker, Sarah Durell. The Institute of Cancer Research and Royal Marsden NHS Foundation Trust: Ros Eeles, Susan Shanley, Nazneen Rahman, Richard Houlston, Elizabeth Bancroft, Lucia D’Mello, Elizabeth Page, Audrey ArdernJones, Anita Mitra, Jennifer Wiggins, Elena Castro. North Trent Clinical Genetics Service, Sheffield: Jackie Cook, Oliver Quarrell, Cathryn Bardsley. South West Thames Regional Genetics Service, London: Shirley Hodgson, Sheila Goff, Glen Brice, Lizzie Winchester. Wessex Clinical Genetics Service. Princess Anne Hospital, Southampton: Diana Eccles, Anneke Lucassen, Gillian Crawford, Emma Tyler, Donna McBride.

The GEMO study (Genetic Modifiers of cancer risk in BRCA1/2 mutation carriers): Cancer Genetics Network 'Groupe Génétique et Cancer', Fédération Nationale des Centres de Lutte Contre le Cancer, France): We thank all the GEMO collaborating members for their contribution to this study. The GEMO study was supported by the Ligue National Contre le Cancer and the Association 'Le cancer du sein, parlons-en!' Award. GEMO collaborating centres are: Coordinating Centres, Unité Mixte de Génétique Constitutionnelle des Cancers Fréquents, Hospices Civils de Lyon/Centre Léon Bérard and UMR5201 CNRS, Université de Lyon, Lyon: Olga Sinilnikova, Laure Barjhoux, Sophie Giraud, Mélanie Léone, Sylvie Mazoyer; and INSERM U509, Service de Génétique Oncologique, Institut Curie, Paris: Dominique Stoppa-Lyonnet, Marion Gauthier-Villars, Claude Houdayer, Virginie Moncoutier, Muriel Belotti, Antoine de Pauw. Institut Gustave Roussy, Villejuif: Brigitte Bressac-de-Paillerets, Audrey Remenieras, Véronique Byrde, Olivier Caron, Gilbert Lenoir. Centre Jean Perrin, Clermont-Ferrand: Yves-Jean Bignon, Nancy Uhrhammer. Centre Léon Bérard, Lyon: Christine Lasset, Valérie Bonadona. Centre François Baclesse, Caen: Agnès Hardouin, Pascaline Berthet. Institut Paoli Calmettes, Marseille: Hagay Sobol, Violaine Bourdon, François Eisinger. Groupe Hospitalier PitiéSalpétrière, Paris: Florence Coulet, Chrystelle Colas, Florent Soubrier. CHU de Arnaud-de-Villeneuve, Montpellier: Isabelle
Coupier. Centre Oscar Lambret, Lille: Jean-Philippe Peyrat, Joëlle Fournier, Françoise Révillion, Philippe Vennin, Claude Adenis. Centre René Huguenin, St Cloud: Etienne Rouleau, Rosette Lidereau, Liliane Demange, Catherine Nogues. Centre Paul Strauss, Strasbourg: Danièle Muller, Jean-Pierre Fricker. Institut Bergonié, Bordeaux: Michel Longy, Nicolas Sevenet. Institut Claudius Regaud, toulouse: Christine Toulas, Rosine Guimbaud, Laurence Gladieff, Viviane Feillel. CHU de Grenoble: Dominique Leroux, Hélène Dreyfus, Christine Rebischung. CHU de Dijon: Cécile Cassini, Laurence Olivier-Faivre. CHU de St-Etienne: Fabienne Prieur. Hôtel Dieu Centre Hospitalier, Chambéry: Sandra Fert Ferrer. Centre Antoine Lacassagne, Nice: Marc Frénay. Creighton University, Omaha, USA: Henry T. Lynch.

Breast Cancer Family Registry (Breast CFR): This work was supported by the National Cancer Institute, National Institutes of Health under RFA-CA-06-503 and through cooperative agreements with members of the Breast Cancer Family Registry and Principal Investigators, including Cancer Care Ontario (U01 CA69467), Columbia University (U01 CA69398), Fox Chase Cancer Center (U01 CA69631), Huntsman Cancer Institute (U01 CA69446), Northern California Cancer Center (U01 CA69417), University of Melbourne (U01 CA69638), and Research Triangle Institute Informatics SupportCenter (RFP No. N02PC45022-46). The content of this manuscript does not necessarily reflect the views or policies of the National Cancer Institute or any of the collaborating centres in the Breast CFR, nor does mention of trade names, commercial products, or organizations imply endorsement by the US Government or the Breast CFR.

The Copenhagen Breast Cancer Study (CBCS) is supported by the Neye Foundation.

Iceland Landspitali - University Hospital study (IUH) is supported by the Research Fund of Landspitali-University Hospital and the Walk together for breast cancer research.

Memorial Sloan-Kettering Cancer Center (MSKCC): acknowledges the support of 'Breast Cancer Research Foundation, Starr Foundation, and the Niehaus Cancer Research Initiative'.

Gynecologic Oncology group (GOG): This study was supported by National Cancer Institute grants to the Gynecologic Oncology Group Administrative Office (CA 27469) and the Gynecologic Oncology Group Statistical and Data Center (CA 37517).

The Ohio State University Clinical Cancer Genetics Program (OSU CCG): This work was funded by the OSU Comprehensive Cancer Center. We thank K Sweet and C Craven for patient accrual and data management, the Human Genetics Sample Bank for sample preparation and the OSU Nucleic Acids Shared Resource for genotyping plate reads.

Istituto Oncologico Veneto (IOVHBOCS): The study was supported by the Ministero dell'Istruzione, dell'Università e della Ricerca (MIUR), Ministero della Sanità, and Alleanza Contro il Cancro.

NN Petrov Institute of Oncology (NNPIO): Supported by grants from the Russian Foundation for Basic Research (grants 08-0400369-a and 09-04-90402-a).

University of Turin Breast Cancer Study (UTBCS): The work of Anna Allavena has been supported by Compagnia di San Paolo (Progetto Oncologia).

$G C-H B O C$ is supported by a grant of the German Cancer Aid (grant107054) to RKS. We thank Juliane Köhler for her excellent technical assistance and the centres of the GC-HBOC for providing samples and clinical data.

Hospital Clínico San Carlos (HCSC): T Caldes and M de Hoya are funded by RD06/0020/0021, FIS 05/0864 (ISCIII, Spain) and FMM 06.

AC Antoniou is a Cancer Research UK Senior Cancer Research Fellow, L McGuffog, the CIMBA genotyping and data management are funded by Cancer Research UK.

\section{Conflict of interest}

The authors declare no conflict of interest. 


\section{REFERENCES}

Antoniou A, Pharoah PD, Narod S, Risch HA, Eyfjord JE, Hopper JL, Loman N, Olsson H, Johannsson O, Borg A, Pasini B, Radice P, Manoukian S, Eccles DM, Tang N, Olah E, Anton-Culver H, Warner E, Lubinski J, Gronwald J, Gorski B, Tulinius H, Thorlacius S, Eerola H, Nevanlinna H, Syrjakoski K, Kallioniemi OP, Thompson D, Evans C, Peto J, Lalloo F, Evans DG, Easton DF (2003) Average risks of breast and ovarian cancer associated with BRCA1 or BRCA2 mutations detected in case Series unselected for family history: a combined analysis of 22 studies. Am J Hum Genet 72: $1117-1130$

Antoniou AC, Goldgar DE, Andrieu N, Chang-Claude J, Brohet R, Rookus MA, Easton DF (2005) A weighted cohort approach for analysing factors modifying disease risks in carriers of high-risk susceptibility genes. Genet Epidemiol 29: 1-11

Antoniou AC, Spurdle AB, Sinilnikova OM, Healey S, Pooley KA, Schmutzler RK, Versmold B, Engel C, Meindl A, Arnold N, Hofmann W, Sutter C, Niederacher D, Deissler H, Caldes T, Kampjarvi K, Nevanlinna H, Simard J, Beesley J, Chen X, Neuhausen SL, Rebbeck TR, Wagner T, Lynch HT, Isaacs C, Weitzel J, Ganz PA, Daly MB, Tomlinson G, Olopade OI, Blum JL, Couch FJ, Peterlongo P, Manoukian S, Barile M, Radice P, Szabo CI, Pereira LH, Greene MH, Rennert G, Lejbkowicz F, Barnett-Griness O, Andrulis IL, Ozcelik H, Gerdes AM, Caligo MA, Laitman Y, Kaufman B, Milgrom R, Friedman E, Domchek SM, Nathanson KL, Osorio A, Llort G, Milne RL, Benitez J, Hamann U, Hogervorst FB, Manders P, Ligtenberg MJ, van den Ouweland AM, Peock S, Cook M, Platte R, Evans DG, Eeles R, Pichert G, Chu C, Eccles D, Davidson R, Douglas F, Godwin AK, Barjhoux L, Mazoyer S, Sobol H, Bourdon V, Eisinger F, Chompret A, Capoulade C, Bressac-de Paillerets B, Lenoir GM, Gauthier-Villars M, Houdayer C, Stoppa-Lyonnet D, Chenevix-Trench G, Easton DF (2008) Common breast cancer-predisposition alleles are associated with breast cancer risk in BRCA1 and BRCA2 mutation carriers. Am J Hum Genet 82: 937-948

Chen S, Iversen ES, Friebel T, Finkelstein D, Weber BL, Eisen A, Peterson LE, Schildkraut JM, Isaacs C, Peshkin BN, Corio C, Leondaridis L, Tomlinson G, Dutson D, Kerber R, Amos CI, Strong LC, Berry DA, Euhus DM, Parmigiani G (2006) Characterization of BRCA1 and BRCA2 mutations in a large United States sample. J Clin Oncol 24: $863-871$

Chenevix-Trench G, Milne RL, Antoniou AC, Couch FJ, Easton DF, Goldgar DE (2007) An international initiative to identify genetic modifiers of cancer risk in BRCA1 and BRCA2 mutation carriers: the Consortium of Investigators of Modifiers of BRCA1 and BRCA2 (CIMBA). Breast Cancer Res 9: 104

Easton DF, Ford D, Bishop DT (1995) Breast and ovarian cancer incidence in BRCA1-mutation carriers. Breast Cancer Linkage Consortium. Am J Hum Genet 56: 265-271

Easton DF, Pooley KA, Dunning AM, Pharoah PD, Thompson D, Ballinger DG, Struewing JP, Morrison J, Field H, Luben R, Wareham N, Ahmed S, Healey CS, Bowman R, Meyer KB, Haiman CA, Kolonel LK, Henderson BE, Le Marchand L, Brennan P, Sangrajrang S, Gaborieau V, Odefrey F, Shen CY, Wu PE, Wang HC, Eccles D, Evans DG, Peto J, Fletcher O, Johnson N, Seal S, Stratton MR, Rahman N, Chenevix-Trench G, Bojesen SE, Nordestgaard BG, Axelsson CK, Garcia-Closas M, Brinton L, Chanock S, Lissowska J, Peplonska B, Nevanlinna H, Fagerholm R, Eerola H, Kang D, Yoo KY, Noh DY, Ahn SH, Hunter DJ, Hankinson SE, Cox DG, Hall P, Wedren S, Liu J, Low YL, Bogdanova N, Schurmann P, Dork T, Tollenaar RA, Jacobi CE, Devilee P, Klijn JG, Sigurdson AJ, Doody MM, Alexander BH, Zhang J, Cox A, Brock IW, MacPherson G, Reed MW, Couch FJ, Goode EL, Olson JE, Meijers-Heijboer $H$, van den Ouweland A, Uitterlinden A, Rivadeneira F, Milne RL, Ribas G, Gonzalez-Neira A, Benitez J, Hopper JL, McCredie M, Southey M, Giles GG, Schroen C, Justenhoven C, Brauch H, Hamann U, Ko YD, Spurdle AB, Beesley J, Chen X, Mannermaa A, Kosma VM, Kataja V, Hartikainen J, Day NE, Cox DR, Ponder BA (2007) Genome-wide association study identifies novel breast cancer susceptibility loci. Nature 447: 1087-1093

Ford D, Easton DF, Stratton M, Narod S, Goldgar D, Devilee P, Bishop DT, Weber B, Lenoir G, Chang-Claude J, Sobol H, Teare MD, Struewing J, Arason A, Scherneck S, Peto J, Rebbeck TR, Tonin P, Neuhausen S, Barkardottir R, Eyfjord J, Lynch H, Ponder BA, Gayther SA, Zelada-Hedman M (1998) Genetic heterogeneity and penetrance analysis of the BRCA1 and BRCA2 genes in breast cancer families. The Breast Cancer Linkage Consortium. Am J Hum Genet 62: 676-689

Garcia-Closas M, Malats N, Real FX, Welch R, Kogevinas M, Chatterjee N, Pfeiffer R, Silverman D, Dosemeci M, Tardon A, Serra C, Carrato A, Garcia-Closas R, Castano-Vinyals G, Chanock S, Yeager M, Rothman N (2006) Genetic variation in the nucleotide excision repair pathway and bladder cancer risk. Cancer Epidemiol Biomarkers Prev 15: $536-542$

Gaudet MM, Milne RL, Cox A, Camp NJ, Goode EL, Humphreys MK, Dunning AM, Morrison J, Giles GG, Severi G, Baglietto L, English DR, Couch FJ, Olson JE, Wang X, Chang-Claude J, Flesch-Janys D, Abbas S, Salazar R, Mannermaa A, Kataja V, Kosma VM, Lindblom A, Margolin S, Heikkinen T, Kampjarvi K, Aaltonen K, Nevanlinna H, Bogdanova N, Coinac I, Schurmann P, Dork T, Bartram CR, Schmutzler RK, Tchatchou S, Burwinkel B, Brauch H, Torres D, Hamann U, Justenhoven C, Ribas G, Arias JI, Benitez J, Bojesen SE, Nordestgaard BG, Flyger HL, Peto J, Fletcher O, Johnson N, Dos Santos Silva I, Fasching PA, Beckmann MW, Strick R, Ekici AB, Broeks A, Schmidt MK, van Leeuwen FE, Van't Veer LJ, Southey MC, Hopper JL, Apicella C, Haiman CA, Henderson BE, Le Marchand L, Kolonel LN, Kristensen V, Grenaker Alnaes G, Hunter DJ, Kraft P, Cox DG, Hankinson SE, Seynaeve C, Vreeswijk MP, Tollenaar RA, Devilee P, Chanock S, Lissowska J, Brinton L, Peplonska B, Czene K, Hall P, Li Y, Liu J, Balasubramanian S, Rafii S, Reed MW, Pooley KA, Conroy D, Baynes C, Kang D, Yoo KY, Noh DY, Ahn SH, Shen CY, Wang HC, Yu JC, Wu PE, Anton-Culver H, Ziogoas A, Egan K, Newcomb P, Titus-Ernstoff L, Trentham Dietz A, Sigurdson AJ, Alexander BH, Bhatti P, Allen-Brady K, Cannon-Albright LA, Wong J, Chenevix-Trench G, Spurdle AB, Beesley J, Pharoah PD, Easton DF, Garcia-Closas M (2009) Five polymorphisms and breast cancer risk: results from the breast cancer association consortium. Cancer Epidemiol Biomarkers Prev 18: $1610-1616$

Hooker S, Bonilla C, Akereyeni F, Ahaghotu C, Kittles RA (2008) NAT2 and NER genetic variants and sporadic prostate cancer susceptibility in African Americans. Prostate Cancer Prostatic Dis 11: 349-356

Kiyohara C, Yoshimasu K (2007) Genetic polymorphisms in the nucleotide excision repair pathway and lung cancer risk: a meta-analysis. Int J Med Sci 4: $59-71$

Lange K, Weeks D, Boehnke M (1988) Programs for pedigree analysis: MENDEL, FISHER, and dGENE. Genet Epidemiol 5: 471-472

Mechanic LE, Millikan RC, Player J, de Cotret AR, Winkel S, Worley K, Heard K, Tse CK, Keku T (2006) Polymorphisms in nucleotide excision repair genes, smoking and breast cancer in African Americans and whites: a population-based case-control study. Carcinogenesis 27: $1377-1385$

Milne RL, Osorio A, Cajal TR, Vega A, Llort G, de la Hoya M, Diez O, Alonso MC, Lazaro C, Blanco I, Sanchez-de-Abajo A, Caldes T, Blanco A, Grana B, Duran M, Velasco E, Chirivella I, Cardenosa EE, Tejada MI, Beristain E, Miramar MD, Calvo MT, Martinez E, Guillen C, Salazar R, San Roman C, Antoniou AC, Urioste M, Benitez J (2008) The average cumulative risks of breast and ovarian cancer for carriers of mutations in BRCA1 and BRCA2 attending genetic counseling units in Spain. Clin Cancer Res 14: $2861-2869$

Milne RL, Ribas G, Gonzalez-Neira A, Fagerholm R, Salas A, Gonzalez E, Dopazo J, Nevanlinna H, Robledo M, Benitez J (2006) ERCC4 associated with breast cancer risk: a two-stage case-control study using highthroughput genotyping. Cancer Res 66: 9420-9427

Moreno V, Gemignani F, Landi S, Gioia-Patricola L, Chabrier A, Blanco I, Gonzalez S, Guino E, Capella G, Canzian F (2006) Polymorphisms in genes of nucleotide and base excision repair: risk and prognosis of colorectal cancer. Clin Cancer Res 12: 2101-2108

Osorio A, Martinez-Delgado B, Pollan M, Cuadros M, Urioste $M$, Torrenteras C, Melchor L, Diez O, De La Hoya M, Velasco E, Gonzalez-Sarmiento R, Caldes T, Alonso C, Benitez J (2006) A haplotype containing the p53 polymorphisms Ins16bp and Arg72Pro modifies cancer risk in BRCA2 mutation carriers. Hum Mutat 27: 242-248

Smith TR, Levine EA, Freimanis RI, Akman SA, Allen GO, Hoang KN, LiuMares W, Hu JJ (2008) Polygenic model of DNA repair genetic polymorphisms in human breast cancer risk. Carcinogenesis 29: $2132-2138$ 